\title{
The magnitude of increased Levothyroxine dose during pregnancy in patients on thyroid-stimulating hormone (TSH) suppression treatment after total thyroidectomy for papillary carcinoma
}

\author{
Mizuho Minakata ${ }^{1)}$, Mitsuru Ito ${ }^{1)}$, Taketoshi Kishi ${ }^{1}$, Mikiko Hada ${ }^{1)}$, Yuzuki Masaki ${ }^{1)}$, \\ Tomohiko Nakamura ${ }^{1)}$, Kazuyoshi Kousaka ${ }^{1)}$, Toshihiko Kasahara ${ }^{1)}$, Takumi Kudo ${ }^{1)}$, Eijun Nishihara ${ }^{1)}$, \\ Shuji Fukata' ${ }^{1)}$, Mitsushige Nishikawa ${ }^{1)}$, Takashi Akamizu ${ }^{1)}$ and Akira Miyauchi' ${ }^{2)}$ \\ 1) Division of Internal Medicine, Center for Excellence in Thyroid Care, Kuma Hospital, Hyogo 650-0011, Japan \\ 2) Division of Surgery and Director, Center for Excellence in Thyroid Care, Kuma Hospital, Hyogo 650-0011, Japan
}

\begin{abstract}
The dose of $\mathrm{L}-\mathrm{T}_{4}$ replacement for hypothyroidism often needs to be increased after pregnancy. In our institution, patients are instructed to double the dose 2 days a week after pregnancy. However, there is scarce evidence supporting the need for a dose increase after pregnancy in patients with preconception thyroid-stimulating hormone (TSH) suppression (TSH $<0.3 \mu \mathrm{IU} / \mathrm{mL}$ ). This study aimed to determine the need for a dose increase in $\mathrm{L}_{-} \mathrm{T}_{4}$ among women with a TSH-suppressive dose of L- $\mathrm{T}_{4}$ before pregnancy. In this retrospective observational study, between January 2008 and December 2018, we analyzed 166 pregnancies in 134 patients on TSH suppression treatment after total thyroidectomy for papillary carcinoma. Thyroid function tests were performed before and in the first trimester of pregnancy. The dose was adjusted and maintained during the first trimester of pregnancy in 76 pregnancies (group A) and 90 pregnancies (group B), respectively. The median serum TSH level was significantly lower in group A than that in group B $(0.014 \mu \mathrm{IU} / \mathrm{mL}$ (IQR, 0.005-0.071) vs. $0.155 \mu \mathrm{IU} / \mathrm{mL}$ (IQR, 0.021-0.657), $p<0.001$ ). TSH suppression could not be maintained after pregnancy in $15.8 \%$ and $38.9 \%$ of the pregnancies in groups A and B, respectively. Increasing the post-pregnancy dose by an average of $27.4 \%$ resulted in maintenance of TSH suppression after pregnancy in $84.2 \%$ of pregnancies. In conclusion, this study suggests that increasing the $\mathrm{L}-\mathrm{T}_{4}$ dose after pregnancy may be appropriate in postoperative thyroid cancer patients whose serum TSH levels should be suppressed.
\end{abstract}

Key words: Thyroid-stimulating hormone suppression, Pregnancy, Papillary carcinoma, Levothyroxine

THYROID HORMONES are important for normal pregnancy and fetal development $[1,2]$. During pregnancy, maternal thyroid hormone requirements increase $[3,4]$. Reference levels of TSH, free $\mathrm{T}_{4}\left(\mathrm{FT}_{4}\right)$ and free $\mathrm{T}_{3}$ $\left(\mathrm{FT}_{3}\right)$ differ between pregnant and non-pregnant populations. The National Health and Nutrition Examination Survey (NHANES) database, a cross-sectional ongoing study, determined trimester-specific means and medians for TSH levels in the U.S. population. In this survey, mean TSH levels were $0.91,1.03$, and $1.32 \mu \mathrm{IU} / \mathrm{mL}$, in each trimester, respectively. Panesar et al. reported trimester-specific TSH reference ranges of the population

Submitted Feb. 6, 2021; Accepted Aug. 16, 2021 as EJ21-0109 Released online in J-STAGE as advance publication Sep. 14, 2021 Correspondence to: Mizuho Minakata, MD, Center for Excellence in Thyroid Care, Kuma Hospital, 8-2-35, Shimoyamate-Dori, Chuo-Ku, Kobe-City, Hyogo 650-0011, Japan.

E-mail: minakata@kuma-h.or.jp without history of thyroid disease were $0.03-2.3 \mu \mathrm{IU} / \mathrm{mL}$ in the first trimester, $0.03-3.1 \mu \mathrm{IU} / \mathrm{mL}$ in the second trimester, $0.13-3.4 \mu \mathrm{IU} / \mathrm{mL}$ in the third trimester [5]. Although the downward shift in TSH reference range is seen in essentially all populations, the extent of this reduction varies significantly between racial and ethnic groups. In a small percentage of women, the TSH can be undetectable $(<0.01 \mu \mathrm{IU} / \mathrm{mL})$ but still represent a normal pregnancy. Subclinical hyperthyroidism has not been associated with adverse pregnancy outcomes. A maternal TSH concentration that is low but detectable is likely not clinically significant [6].

Athyroid patients after total thyroidectomy are dependent on exogenous L-thyroxine $\left(\mathrm{L}-\mathrm{T}_{4}\right)$. The magnitude of increased $\mathrm{L}_{-} \mathrm{T}_{4}$ requirements in hypothyroid pregnant women depends upon the etiology of the hypothyroidism [7]. However, the appropriate timing for the dose increase is still unclear. Some authors argue that 
L- $\mathrm{T}_{4}$ dose increases during pregnancy should be determined from thyroid function test results, while others suggest increasing the dose as soon as pregnancy is confirmed $[8,9]$. There are no reports directly comparing pregnancy outcomes between these two methods of dose escalation. In addition, there are few studies of pregnancy in postoperative thyroid cancer patients on TSH suppression therapy. Krhin et al. reported 36 cases of pregnancy after total thyroidectomy for thyroid cancer [10]. They evaluated patients who had received a TSHsuppressive dose of ${\mathrm{L}-\mathrm{T}_{4}}_{4}$ prior to pregnancy and adjusted their medications to maintain serum TSH levels below $0.3 \mu \mathrm{IU} / \mathrm{mL}$ by checking blood test every 6 to 8 weeks. Serum TSH levels were adequately suppressed in only $25 \%$ of the pregnancies, and the ranges of changes in TSH concentrations during pregnancy varied widely. This study aimed to determine (1) whether there is a need to increase the $\mathrm{L}-\mathrm{T}_{4}$ dose after pregnancy to prevent TSH elevation among postoperative thyroid cancer women who are on TSH suppression prior to pregnancy and (2) the extent of dose increase after pregnancy.

\section{Materials and Methods}

\section{Study design and patients}

This retrospective observational study analyzed 166

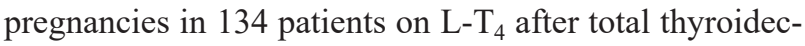
tomy for papillary carcinoma at Kuma Hospital. The patients were selected from those who visited the hospital during their pregnancy between 2008 and 2018. Eligible patients were identified through a search of the computerized medical record system, and only those who were followed for postoperative hypothyroidism prior to pregnancy and were on a TSH-suppressive dose of ${\mathrm{L}-\mathrm{T}_{4}}_{4}$ before pregnancy were included. The preconception goal for TSH was less than $0.3 \mu \mathrm{IU} / \mathrm{mL}$ in the absence of recurrence based upon imaging studies and stimulated thyroglobulin levels. Some patients were instructed in advance to self-titrate their ${\mathrm{L}-\mathrm{T}_{4}}_{4}$ to double their dose 2 days a week after pregnancy. Meanwhile, the dose was only adjusted in some patients after their serum TSH levels were checked at the time of pregnancy visits. In either case, patients came to the hospital for consultation in the first trimester of pregnancy and continued to have regular visits during pregnancy and after childbirth. Thyroid function tests were performed before and during pregnancy.

The patients were divided into two groups based on whether they self-adjusted their ${\mathrm{L}-\mathrm{T}_{4}}_{4}$ dose in the early pregnancy period (group A) or not (group B). Specifically, group A involved patients who self-increased their dose before they first visit to the hospital in the first trimester of pregnancy. Meanwhile, group B involved patients who maintained their dose before consultation. In each group, the ${\mathrm{L}-\mathrm{T}_{4}}_{4}$ dose was adjusted individually to maintain the serum TSH below $0.3 \mu \mathrm{IU} / \mathrm{mL}$ during pregnancy.

We evaluated thyroid function in the first trimester of pregnancy and ${\mathrm{L}-\mathrm{T}_{4}}_{4}$ dose change in both groups. Percent increases in $\mathrm{L}_{-} \mathrm{T}_{4}$ dose were calculated as cumulative increases from baseline.

This study was reviewed and approved by the Ethical Committee at Kuma Hospital (the approval number 20200709-1), and all patients gave written informed consent.

\section{Serum hormone measurements}

All blood samples for all hormone levels were obtained at Kuma Hospital. TSH, $\mathrm{FT}_{4}$ and $\mathrm{FT}_{3}$ levels were measured using chemiluminescent immunoassays with ARCHITECT i2000SR (Abbott, Japan) (normal range: $\mathrm{TSH}, 0.3-5.0 \mu \mathrm{IU} / \mathrm{mL} ; \mathrm{FT}_{4}, 0.7-1.6 \mathrm{ng} / \mathrm{dL}$; and $\left.\mathrm{FT}_{3}, 1.7-3.7 \mathrm{pg} / \mathrm{mL}\right)$.

\section{Statistical analysis}

Data in both groups were not-normally distributed, and thus the Mann-Whitney $U$ test was used for between-group comparisons. ${\mathrm{L}-\mathrm{T}_{4}}_{4}$ dose changes throughout the pregnancy in each group were analyzed using the Wilcoxon signed rank test. All statistical analyses were performed using the Excel statistical software package (BellCurve for Excel; Social Survey Research Information Co., Ltd. Tokyo, Japan). A $p$-value of $<0.05$ was considered statistically significant.

\section{Results}

In total, 107 patients were followed through one pregnancy; 23 patients, two pregnancies; 3 patients, three pregnancies; and 1 patient, four pregnancies. The mean patient age was 32.7 years (range, 19-43 years). At the point of pregnancy, three patients had lung metastasis and three patients had mediastinal or cervical lymph node metastasis. However, there was no evidence of progression during pregnancy by thyroid ultrasonography or serum thyroglobulin levels.

Groups A and B involved 76 and 90 pregnancies, respectively. There was no significant between-group difference with respect to the maternal age, prepregnancy $\mathrm{L}_{-} \mathrm{T}_{4}$ dose, and serum TSH level (Table 1). Only the serum $\mathrm{FT}_{3}$ level was higher in group B. Table 2 shows the gestational weeks; ${\mathrm{L}-\mathrm{T}_{4}}_{4}$ dose before consultation; ${\mathrm{L}-\mathrm{T}_{4}}_{4}$ dose instructed by the individual practitioners at consultation; the serum $\mathrm{TSH}, \mathrm{FT}_{4}$ and $\mathrm{FT}_{3}$ levels in the first trimester of pregnancy; and ${\mathrm{L}-\mathrm{T}_{4}}_{4}$ dose at delivery.

Among 42 pregnancies in Group A, the median 
Table 1 Baseline characteristics of the patients

\begin{tabular}{|c|c|c|c|}
\hline Characteristics & Group $A(n=76)$ & Group B $(n=90)$ & $p$ value \\
\hline Age (years) & $33(30-37)$ & $31(29-35)$ & 0.06 \\
\hline Baseline $\mathrm{L}^{-\mathrm{T}_{4}}$ dose ( $\mu \mathrm{g} /$ day $)$ & $125(100-128)$ & $125(100-134)$ & 0.7 \\
\hline Baseline TSH level $(\mu \mathrm{IU} / \mathrm{mL})$ & $0.025(0.009-0.062)$ & $0.028(0.011-0.099)$ & 0.7 \\
\hline Baseline $\mathrm{FT}_{4}$ level (ng/dL) & $1.44(1.33-1.54)$ & $1.44(1.34-1.58)$ & 0.5 \\
\hline Baseline $\mathrm{FT}_{3}$ level $(\mathrm{pg} / \mathrm{mL})$ & $2.77(2.52-2.95)$ & $2.91(2.71-3.16)$ & 0.02 \\
\hline \multicolumn{4}{|l|}{ Radioiodine ablation } \\
\hline Treated $(n) /$ untreated $(n)$ & $14 / 62$ & $21 / 69$ & 0.3 \\
\hline
\end{tabular}

Table 2 Adequacy of $\mathrm{L}-\mathrm{T}_{4}$ dose and thyroid function at the time of consultation in the first trimester of pregnancy

\begin{tabular}{|c|c|c|c|}
\hline & Group $A(n=76)$ & Group B $(n=90)$ & $p$ value \\
\hline Pregnancy weeks in the first trimester (week) & $7(6-9)$ & $6(5-8)$ & $<0.001$ \\
\hline $\mathrm{L}-\mathrm{T}_{4}$ dose before consultation ( $\mu \mathrm{g} /$ day) & $161(129-165)$ & $125(100-134)$ & $<0.001$ \\
\hline $\mathrm{L}^{-\mathrm{T}_{4}}$ dose after consultation ( $\mu \mathrm{g} /$ day) & $150(129-161)$ & $129(125-158)$ & $<0.001$ \\
\hline \multicolumn{4}{|c|}{ Changes in $\mathrm{L}_{-} \mathrm{T}_{4}$ dose before and after consultation $(n, \%)$} \\
\hline increase & $7(9)$ & $53(59)$ & \\
\hline same dose & $48(63)$ & $36(40)$ & \\
\hline decrease & $21(27)$ & $1(1)$ & \\
\hline TSH levels in the first trimester $(\mu \mathrm{IU} / \mathrm{mL})$ & $0.014(0.005-0.071) *$ & $0.155(0.021-0.657)$ & $<0.001$ \\
\hline $\mathrm{TSH}<0.003(n, \%)$ & $8(10.5)$ & $2(2.2)$ & \\
\hline $\mathrm{TSH}>0.3(n, \%)$ & $12(15.8)$ & $35(38.9)$ & \\
\hline $\mathrm{TSH}>2.5(n, \%)$ & $0(0)$ & $11(12.2)$ & \\
\hline $\mathrm{FT}_{4}$ level in the first trimester $(\mu \mathrm{IU} / \mathrm{mL})$ & $1.53(1.41-1.67)$ & $1.33(1.19-1.51)$ & $<0.001$ \\
\hline $\mathrm{FT}_{3}$ level in the first trimester $(\mathrm{pg} / \mathrm{mL})$ & $2.70(2.51-3.00)$ & $2.64(2.45-2.82)$ & 0.2 \\
\hline $\mathrm{L}-\mathrm{T}_{4}$ dose at the time of delivery ( $\mu \mathrm{g} /$ day) & $150(129-162)$ & $150(125-161)$ & 0.03 \\
\hline
\end{tabular}

Statistical significance was analyzed using the unpaired $t$-test, or Mann-Whitney $U$ test. Values are expressed as median (IQR). *In 42 pregnancies in group A, we were able to identify how many days after self-increasing L-T 4 dose patients visited the hospital, with a median of 18 days (IQR, 10-30 days).

number of days from self-increasing $\mathrm{L}_{-} \mathrm{T}_{4}$ dose by patients to hospital visit was 18 days (IQR, 10-30 days). Patients in group B visited the hospital earlier than in group A during the first trimester of pregnancy ( $p<$ $0.001)$. At the time of consultation, patients in group B had significantly lower $\mathrm{L}_{-} \mathrm{T}_{4}$ dose $(p<0.001)$, higher serum TSH levels $(p<0.001)$, and lower serum $\mathrm{FT}_{4}$ levels $(p<0.001)$ than those in group A.

The $\mathrm{L}-\mathrm{T}_{4}$ dose of all patients was adjusted by their attending physician in the first trimester of pregnancy and increased if TSH suppression was not maintained at the time of the visit, or TSH suppression was maintained at a very mild degree. In group $A$, the dose was decreased in 21 pregnancies and increased in 7. In group $\mathrm{B}$, the dose was decreased in 1 pregnancy and increased in 53 pregnancies. The dose in group A was reduced because 12 of 21 patients had serum $\mathrm{FT}_{4}$ level $>1.6 \mathrm{ng} / \mathrm{dL}$ at the time of visit and were judged to have excessive doses. The convenience of medication administration was considered in the remaining 9 pregnancies. TSH suppression therapy was unsuccessful in the first trimester of pregnancy in $12(15.8 \%)$ pregnancies in group A and 35 (38.9\%) pregnancies in group B.

The changes in serum TSH, $\mathrm{FT}_{4}$, and $\mathrm{FT}_{3}$ levels before pregnancy and in the first trimester in each group are presented in Figs. 1 and 2. Group A showed no significant difference in serum TSH levels between before and during the first trimester of pregnancy $(p=0.4)$. The serum $\mathrm{FT}_{4}$ and $\mathrm{FT}_{3}$ levels were slightly elevated in the first trimester of pregnancy $(p<0.001, p=0.006$, respectively). Meanwhile, the serum TSH levels were significantly higher $(p<0.001)$ and the serum $\mathrm{FT}_{4}$ and 

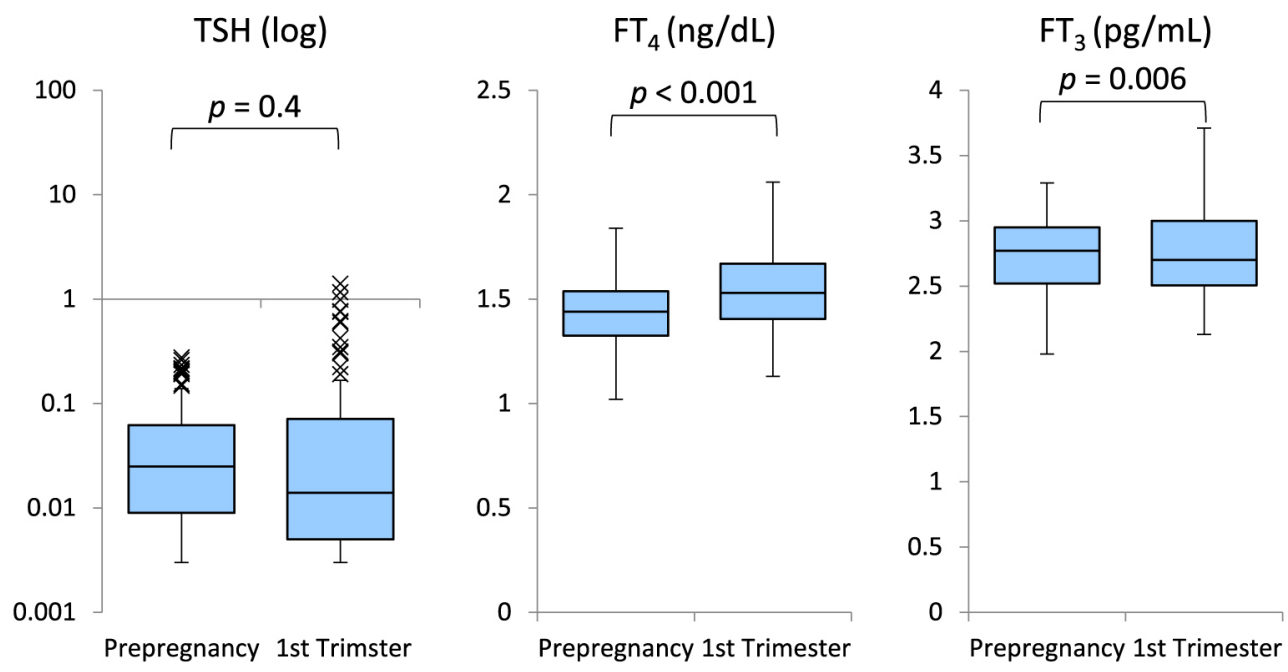

Fig. $1 \mathrm{TSH}, \mathrm{FT}_{4}$ and $\mathrm{FT}_{3}$ levels in group A before and after pregnancy.

The serum TSH levels were measured in all 76 cases in group A (range: before pregnancy $<0.003-0.277 \mu \mathrm{IU} / \mathrm{mL}$, after pregnancy $<0.003-1.4 \mu \mathrm{IU} / \mathrm{mL}$ ). The serum $\mathrm{FT}_{4}$ levels were measured in 66 cases before pregnancy and in 63 cases during the first trimester of pregnancy. The serum $\mathrm{FT}_{3}$ values were measured in 41 cases before pregnancy and in 46 cases in the first trimester of pregnancy. The serum $\mathrm{TSH}, \mathrm{FT}_{4}$ and $\mathrm{FT}_{3}$ levels before and after pregnancy were compared using Wilcoxon's signed rank test.
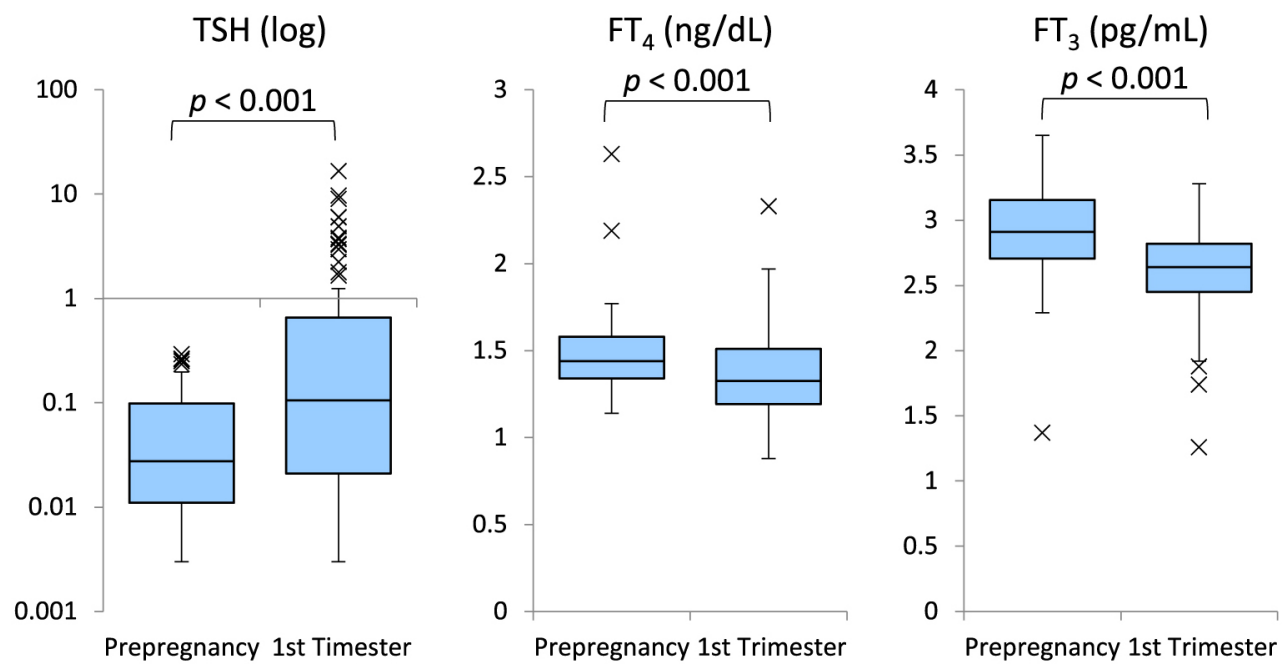

Fig. $2 \mathrm{TSH}, \mathrm{FT}_{4}$ and $\mathrm{FT}_{3}$ levels in group $\mathrm{B}$ before and after pregnancy.

The serum TSH levels were measured in all 90 cases in group B (range: before pregnancy $<0.003-0.293 \mu \mathrm{IU} / \mathrm{mL}$, after pregnancy $<0.003-16.6 \mu \mathrm{IU} / \mathrm{mL}$ ). The serum $\mathrm{FT}_{4}$ levels were measured in 81 cases before pregnancy and in 78 cases during the first trimester of pregnancy. The serum $\mathrm{FT}_{3}$ values were measured in 39 cases before pregnancy and in 43 cases in the first trimester of pregnancy. The serum $\mathrm{TSH}, \mathrm{FT}_{4}$ and $\mathrm{FT}_{3}$ levels before and after pregnancy were compared using Wilcoxon's signed rank test.

$\mathrm{FT}_{3}$ levels were significantly lower $(p<0.001$ and $p<$ 0.001 ) in the first trimester of pregnancy in group B.

The changes in $\mathrm{L}-\mathrm{T}_{4}$ dose before and during pregnancy in each group are presented in Fig. 3. The L-T dose after consultation in the first trimester was significantly higher than that before pregnancy in both groups (all $p<0.001$ ). The $\mathrm{L}_{-} \mathrm{T}_{4}$ dose was self-increased by an average of $27.4 \%$ in group A. In detail, 71 of the 76 patients in group A took the double dose two days weekly, two took the dose at the time of their previous pregnancy. One accidentally took the double dose one day weekly, one increased the double dose from one day weekly before pregnancy to three days, and one took the dose as directed by the obstetrician. The dose was increased after consultation in the first trimester to $24.5 \%$ and $14.6 \%$ higher than that before pregnancy in groups A and B, respectively. The mean increase in $\mathrm{L}-\mathrm{T}_{4}$ dose after pregnancy was lower in group $\mathrm{B}$ than in group 

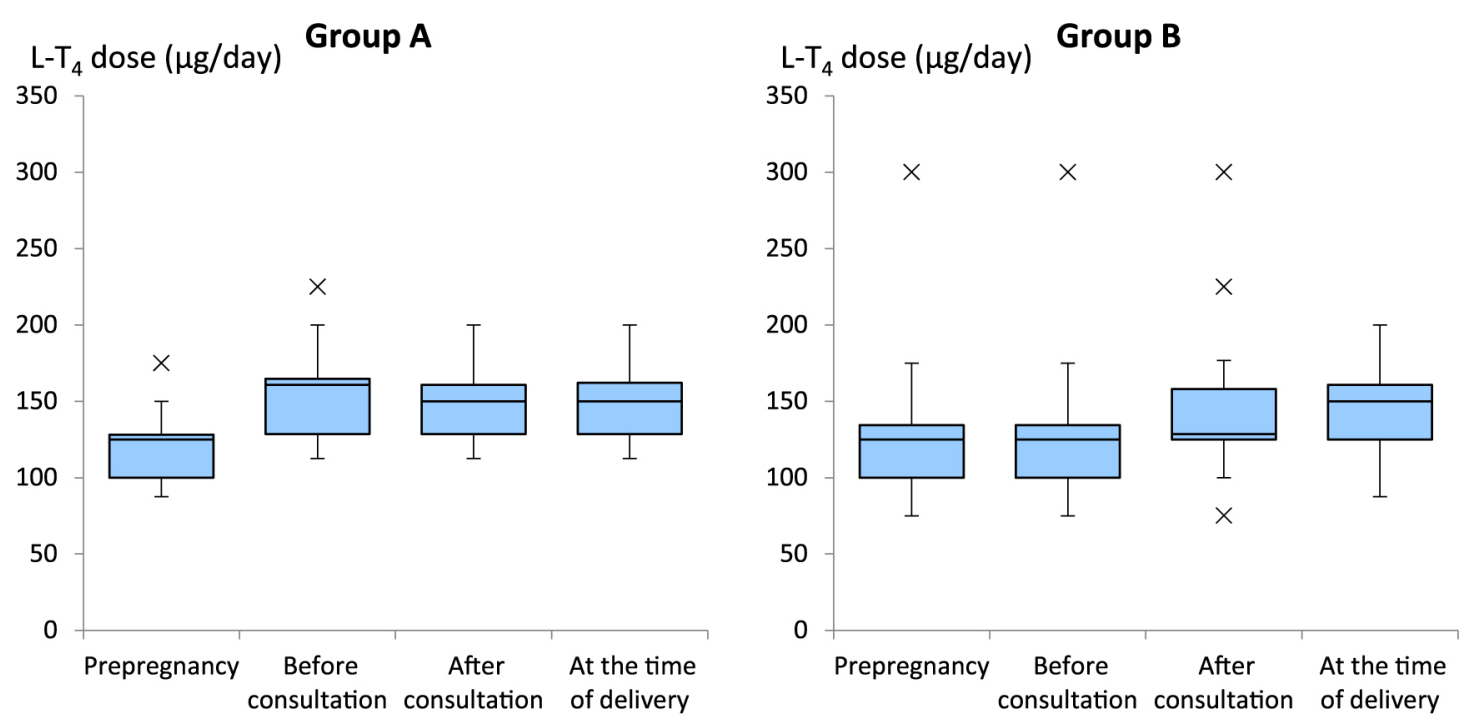

Fig. 3 Changes of $\mathrm{L}-\mathrm{T}_{4}$ dosage during pregnancy of each group.

The bottom and top of the box are the $25^{\text {th }}$ and $75^{\text {th }}$ percentile (the lower and upper quartiles, respectively). The band near the middle of the box is the $50^{\text {th }}$ percentile (median). The ends of the whiskers represent the minimum and maximum of all the data. The Cross marks are outliers. The number of weeks of pregnancy in "After consultation" corresponds to "Pregnancy weeks in the first trimester" in Table 2.

A because $40 \%$ of the patients continued the same dose. However, when restricted to only those patients who increased their dose at the time of consultation, the average increase in $\mathrm{L}-\mathrm{T}_{4}$ dose from pre-pregnancy to the first trimester in group $\mathrm{B}$ was $25.6 \%$. The median $\mathrm{L}^{-\mathrm{T}_{4}}$ dose in the overall pregnancies with suppressive TSH levels was $125 \mu \mathrm{g} /$ day before pregnancy and was $142.9 \mu \mathrm{g} / \mathrm{day}$ in the first trimester of pregnancy.

The miscarriage rate was $7.9 \%$ in group A and $18.9 \%$ in group B (odds ratio: $2.7,95 \%$ confidence interval: 1.01-7.28), and was significantly higher in group B. The preterm birth rate was $5.7 \%$ in group A and $13.7 \%$ in group B (odds ratio: $2.6,95 \%$ confidence interval: 0.78 8.78), without significant difference. The median ${\mathrm{L}-\mathrm{T}_{4}}_{4}$ dose at delivery was $150 \mu \mathrm{g} /$ day (IQR: $129-162 \mu \mathrm{g} /$ day) in group A and $150 \mu \mathrm{g} /$ day (IQR: $125-161 \mu \mathrm{g} /$ day) in group $\mathrm{B}$. The $\mathrm{L}-\mathrm{T}_{4}$ dose at delivery was significantly higher in group A than that in group B $(p=0.03)$. No patients in both groups had any new cancer recurrence or metastatic growth findings during pregnancy.

\section{Discussion}

Current guidelines of American Thyroid Association and the Japanese Association of Endocrine Surgeons state that patients with a history of thyroid cancer should

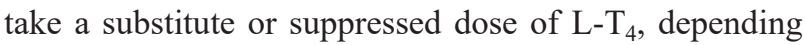
on their risk [11, 12]. However, the appropriateness of a dose increase in $\mathrm{L}_{-} \mathrm{T}_{4}$ in this population is yet to be established. This study found that among patients who were TSH suppressed before pregnancy, the serum TSH levels were significantly increased and the $\mathrm{FT}_{4}$ and $\mathrm{FT}_{3}$ levels were significantly decreased in the first trimester of pregnancy if the $\mathrm{L}-\mathrm{T}_{4}$ doses were not increased after pregnancy. When the average $\mathrm{L}^{-} \mathrm{T}_{4}$ dose was increased by $27.4 \%$ immediately after pregnancy, the TSHsuppressed status was maintained after pregnancy in $84.2 \%$ of pregnancies.

The Endocrine Society Clinical Practice Guidelines recommended that $\mathrm{L}-\mathrm{T}_{4}$ dose should be increased at 4-6 weeks of gestation [13], with an additional dose of 30$50 \%$ required $[3,4]$. However, the most appropriate timing for increasing the $\mathrm{L}_{-} \mathrm{T}_{4}$ dose, that is, immediately after pregnancy or when elevation of serum TSH level is observed, is still unclear [14]. Alexander et al. prospectively evaluated 20 pregnancies with hypothyroidism, including Hashimoto's disease, thyroid cancer, Graves' disease, and benign thyroid nodules [8]. The $\mathrm{L}^{-} \mathrm{T}_{4}$ requirements increased starting from 5 weeks' gestation, and thus they recommended increasing the dose by about $30 \%$ as early as possible after pregnancy. Yassa et al. also conducted a prospective randomized trial of increasing $\mathrm{L}_{-} \mathrm{T}_{4}$ in early pregnancy in patients with mostly Hashimoto's disease [9]. They found that increasing the

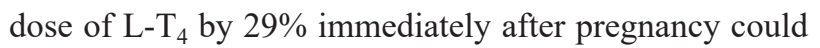
achieve a TSH level of $<2.5 \mu \mathrm{IU} / \mathrm{mL}$ in $85 \%$ of patients and $<5.0 \mu \mathrm{IU} / \mathrm{mL}$ in $100 \%$ of the patients.

However, there are few reports on post-pregnancy L$\mathrm{T}_{4}$ adjustment in patients who are athyroid and have suppressed TSH levels before pregnancy. Lor et al. found 
that when postoperative thyroid cancer patients adjusted their $\mathrm{L}-\mathrm{T}_{4}$ dose to maintain their TSH target range of 0.4 to $4.1 \mu \mathrm{IU} / \mathrm{mL}$ during pregnancy, the mean cumulative dose gain during pregnancy was $9 \%, 21 \%$, and $26 \%$ in each trimester [7]. Some patients did not need to increase their doses. Only patients with a pre-pregnancy TSH level of $0.01-0.4 \mu \mathrm{IU} / \mathrm{mL}$ were able to maintain their serum TSH levels in the target range after pregnancy without increasing the $\mathrm{L}_{-} \mathrm{T}_{4}$ dose. However, they considered that if the TSH-suppressed state needs to be maintained during pregnancy, the $\mathrm{L}_{-} \mathrm{T}_{4}$ dose may need to be increased after pregnancy. Krhin et al. adjusted the $\mathrm{L}_{-} \mathrm{T}_{4}$ dose after pregnancy to maintain the TSH between 0.01 and $0.29 \mu \mathrm{IU} / \mathrm{mL}$ in patients who underwent total thyroidectomy and radioiodine ablation of the thyroid remnant. The TSH-suppressed status prior to pregnancy was maintained during pregnancy in $25 \%$ of the patients, and they did not require an increase in their L-T4 dose [10]. The degree of dose increase was small $(11 \%)$, and similar to Loh et al. [7], they pointed out that increasing ${\mathrm{L}-\mathrm{T}_{4}}_{4}$ dose immediately after pregnancy can lead to overtreatment and development of thyrotoxicosis. However, the range of changes in TSH level during pregnancy was significantly wide in the patients on suppressive $\mathrm{L}_{-} \mathrm{T}_{4}$ therapy before conception, and the rate at which TSH was adequately suppressed during pregnancy was low.

In our study, among the patients with suppressed TSH levels prior to pregnancy who maintained the same $\mathrm{L}_{-} \mathrm{T}_{4}$ dose after pregnancy, $41 \%$ did not require dose escalation in the first trimester of pregnancy. However, if the $\mathrm{L}-\mathrm{T}_{4}$ dose was not increased early in the pregnancy, the rate of failure to achieve TSH suppression during pregnancy was higher. TSH suppression was not achieved in $38.9 \%$ of pregnancies in group B. It is assumed that increasing the $\mathrm{L}_{-} \mathrm{T}_{4}$ dose soon after pregnancy may help maintain TSH suppression in the early pregnancy period. However, the normal range of thyroid function indicators during early pregnancy in athyroid patients is unknown. Moreover, the effect of increasing the $\mathrm{L}_{-} \mathrm{T}_{4}$ dose in the early pregnancy on pregnancy outcomes is still unclear. All previous reports have enrolled only a small number of cases in which the cause of hypothyroidism was postoperative thyroid cancer, and there were few miscarriage cases $[7,9,10]$. In our study, the possibility of overtreatment with empirical dose increase of $\mathrm{L}_{-} \mathrm{T}_{4}$ after pregnancy and any adverse effect on pregnancy due to over-supplementation was unclear. Maternal subclinical hyperthyroidism was likely not associated with adverse pregnancy outcomes [6]. TSH level below $0.20 \mu \mathrm{IU} / \mathrm{mL}$ was not associated with an increased risk of miscarriage in patients on $\mathrm{L}-\mathrm{T}_{4}$ supplementation [15].

Conversely, it has been reported that women on $\mathrm{L}_{-} \mathrm{T}_{4}$ supplementation with TSH below $0.1 \mu \mathrm{IU} / \mathrm{mL}$ have an increased odds of preterm birth [16]. However, the report by Lemieux et al. does not discuss the pregnancy course for each cause of hypothyroidism. It does not evaluate whether there is a correlation between TSH below $0.1 \mu \mathrm{IU} / \mathrm{mL}$ during pregnancy and preterm birth rate in patients even after thyroid cancer surgery. If the L-T4 dose is not increased early after pregnancy in postoperative thyroid cancer patients, TSH suppression might not be achieved, as reported by Krhin et al. [10]. Our study shows that an increase in the average $\mathrm{L}_{-} \mathrm{T}_{4}$ dose by $27.4 \%$ immediately after pregnancy results in maintaining TSH-suppressed status after pregnancy in $84.2 \%$. Although pregnancy outcomes, such as birth weight, fetal growth, and perinatal complications, were not compared, there was no increase in miscarriage or preterm birth rates.

Collectively, our findings and those of previous studies [17-19] show that among athyroid patients after total thyroidectomy and are on $\mathrm{L}_{-} \mathrm{T}_{4}$ therapy, those with suppressed serum TSH levels have normal serum $\mathrm{FT}_{3}$ levels and mildly high serum $\mathrm{FT}_{4}$ levels. Further, the presence of biochemical markers $[19,20]$ or symptoms [21] related to thyroid function studies in such patients indicate that patients with a low TSH have lower risks of developing hyperthyroid symptoms. Therefore, a low TSH level with normal serum $\mathrm{FT}_{3}$ levels and mildly high $\mathrm{FT}_{4}$ levels during pregnancy may be advantageous for maintaining the pregnancy and providing sufficient $T_{4}$ for the fetus. To our best knowledge, there are no studies on the associations between ${\mathrm{L}-\mathrm{T}_{4}}_{4}$ dose adjustment during early pregnancy and miscarriage rate in post-total thyroidectomy patients. This needs to be investigated in future research.

This study has some limitations. First, cases who had miscarried in the very early stage of pregnancy before consultation and whose post-pregnancy serum TSH levels could not confirmed were excluded. This may have affected the miscarriage rate in each group. Second, the frequency of revisits to the hospital after the first trimester of pregnancy varied with each clinician. Krhin et al. reported that post-pregnancy thyroid function testing every 6 to 8 weeks failed to achieve TSH suppression during pregnancy in $75 \%$ of the patients, and $14 \%$ of them had elevated TSH levels above the normal range [10]. The American Thyroid Association (ATA) guidelines recommend that serum TSH levels should be monitored approximately every 4 weeks until 16-20 weeks of gestation, and at least once between 26 and 32 weeks of gestation [22]. In our study, it cannot be ruled out that the patients in both groups may have been under- or over-treated during pregnancy. This may be avoided by performing thyroid function tests every 4 weeks as recommended by ATA guidelines [22] and Yassa et al. [9]. 
The reason for significantly lower $\mathrm{L}_{-} \mathrm{T}_{4}$ dose at delivery in group B than in group A may be because some patients were not opportune to receive dose adjustment after their hospital visit in the first trimester. If thyroid function tests were performed every 4 weeks during pregnancy, the $\mathrm{L}_{-} \mathrm{T}_{4}$ doses in both groups might have been similar.

In conclusion, postoperative athyreotic patients taking TSH-suppressive dose of ${\mathrm{L}-\mathrm{T}_{4}}_{4}$ need to increase their dose early after pregnancy to prevent TSH elevation. By increasing $\mathrm{L}_{-} \mathrm{T}_{4}$ dose by an average of $27.4 \%$ immediately after pregnancy, $84.2 \%$ of patients could maintain TSH suppression in the first trimester. The thyroid function of postoperative thyroid cancer patients on high doses of $\mathrm{L}-\mathrm{T}_{4}$ should be closely monitored during preg- nancy because subsequent dose changes may be required to maintain adequate TSH levels.

\section{Acknowledgments}

Author contributions: M. Minakata and M. Ito constructed this study design. M. Minakata analyzed the data. The other co-authors contributed by administering patient care.

\section{Disclosure}

None of the authors have any potential conflicts of interest associated with this research.

\section{References}

1. Leung AS, Millar LK, Koonings PP, Montoro M, Mestman JH (1993) Perinatal outcome in hypothyroid pregnancies. Obstet Gynecol 81: 349-353.

2. Haddow JE, Palomaki GE, Allan WC, Williams JR, Knight GJ, et al. (1999) Maternal thyroid deficiency during pregnancy and subsequent neuropsychological development of the child. N Engl J Med 341: 549-555.

3. Kaplan MM (1992) Monitoring thyroxine treatment during pregnancy. Thyroid 2: 147-152.

4. Mandel SJ, Larsen PR, Seely EW, Brent GA (1990) Increased need for thyroxine during pregnancy in women with primary hypothyroidism. $N$ Engl J Med 323: 91-96.

5. Panesar NS, Li CY, Rogers MS (2001) Reference intervals for thyroid hormones in pregnant Chinese women. Ann Clin Biochem 38: 329-332.

6. Casey BM, Dashe JS, Wells CE, McIntire DD, Leveno KJ, et al. (2006) Subclinical hyperthyroidism and pregnancy outcomes. Obstet Gynecol 107: 337-341.

7. Loh JA, Wartofsky L, Jonklaas J, Burman KD (2009) The magnitude of increased levothyroxine requirements in hypothyroid pregnant women depends upon the etiology of the hypothyroidism. Thyroid 19: 269-275.

8. Alexander EK, Marqusee E, Lawrence J, Jarolim P, Fischer GA, et al. (2004) Timing and magnitude of increase in levothyroxine requirements during pregnancy in women with hypothyroidism. $N$ Engl J Med 351: 241249.

9. Yassa L, Marqusee E, Fawcett R, Alexander EK (2010) Thyroid hormone early adjustment in pregnancy (the THERAPY) trial. J Clin Endocrinol Metab 95: 3234 3241.

10. Krhin B, Besic N (2012) Effectiveness of L-thyroxine treatment on TSH suppression during pregnancy in patients with a history of thyroid carcinoma after total thyroidectomy and radioiodine ablation. Radiol Oncol 46: $160-165$.
11. Haugen BR, Alexander EK, Bible KC, Doherty GM, Mandel SJ, et al. (2016) 2015 American Thyroid Association management guidelines for adult patients with thyroid nodules and differentiated thyroid cancer: The American Thyroid Association Guidelines Task Force on thyroid nodules and differentiated thyroid cancer. Thyroid 26: 1133.

12. Ito $\mathrm{Y}$, Onoda $\mathrm{N}$, Okamoto $\mathrm{T}$ (2020) The revised clinical practice guidelines on the management of thyroid tumors by the Japan Associations of Endocrine Surgeons: Core questions and recommendations for treatments of thyroid cancer. Endocr J 67: 669-717.

13. Groot LD, Abalovich M, Alexander EK, Amino N, Barbour L, et al. (2012) Management of thyroid dysfunction during pregnancy and postpartum: an Endocrine Society clinical practice guideline. J Clin Endocrinol Metab 97: 2543-2565.

14. Toft A (2004) Increased levothyroxine requirements in pregnancy-why, when, and how much? N Engl J Med 351: 292-294.

15. Taylor PN, Minassian C, Rehman A, Iqbal A, Draman MS, et al. (2014) TSH levels and risk of miscarriage in women on long-term levothyroxine: a community-based study. J Clin Endocrinol Metab 99: 3895-3902.

16. Lemieux P, Yamamoto JM, Nerenberg KA, Metcalfe A, Chin A, et al. (2021) Thyroid laboratory testing and management in women on thyroid replacement before pregnancy and associated pregnancy outcomes. Thyroid 31: 841-849.

17. Ito M, Miyauchi A, Morita S, Kudo T, Nishihara E, et al. (2012) TSH-suppressive doses of levothyroxine are required to achieve preoperative native serum triiodothyronine levels in patients who have undergone total thyroidectomy. Eur J Endocrinol 167: 373-378.

18. Gullo D, Latina A, Frasca F, Le Moli R, Pellegriti G, et al. (2011) Levothyroxine monotherapy cannot guarantee 
euthyroidism in all athyreotic patients. PLoS One 6: e22552.

19. Werneck de Castro JP, Fonseca TL, Ueta CB, McAninch EA, Abdalla S, et al. (2015) Differences in hypothalamic type 2 deiodinase ubiquitination explain localized sensitivity to thyroxine. J Clin Invest 125: 769-781.

20. Ito M, Miyauchi A, Hisakado M, Yoshioka W, Ide A, et al. (2017) Biochemical markers reflecting thyroid function in athyreotic patients on levothyroxine monotherapy. Thyroid 27: 484-490.
21. Ito M, Miyauchi A, Hisakado M, Yoshioka W, Kudo T, et al. (2019) Thyroid function related symptoms during levothyroxine monotherapy in athyreotic patients. Endocr $J$ 66: 953-960.

22. Alexander EK, Pearce EN, Brent GA, Brown RS, Chen H, et al. (2017) 2017 Guidelines of the American Thyroid Association for the diagnosis and management of thyroid disease during pregnancy and the postpartum. Thyroid 27: 315-389. 